\title{
Smoke, Biomass Exposure, and COPD Risk in the Primary Care Setting: The PUMA Study
}

\author{
Maria Montes de Oca MD, Gustavo Zabert MD, Dolores Moreno MD, \\ Maria E Laucho-Contreras MD, Maria Victorina Lopez Varela MD, and Filip Surmont MD
}

\begin{abstract}
BACKGROUND: The evidence indicates that risk factors other than smoking are important in the development of COPD. It has been postulated that less traditional risk factors (eg, exposure to coal and/or biomass smoke) may interact with smoking to further increase COPD risk. This analysis evaluated the effect of exposure to biomass and smoking on COPD risk in a primary care setting in Latin America. METHODS: Subjects attending routine primary care visits, $\mathbf{2} 40$ y old, who were current or former smokers or were exposed to biomass smoke, completed a questionnaire and performed spirometry. COPD was defined as post-bronchodilator $\mathrm{FEV}_{1} / \mathrm{FVC}<0.70$ and the lower limit of normal. Smoking was defined by pack-years $(\leq 20,20-30$, or $>30)$, and biomass exposure was defined as an exposure to coal or wood (for heating, cooking, or both) for $\geq 10 \mathrm{y}$. RESULTS: One thousand seven hundred forty-three individuals completed the questionnaire, and 1,540 performed spirometry. Irrespective of COPD definition, approximately $40 \%$ of COPD subjects reported exposure to biomass versus $30 \%$ of those without COPD. A higher proportion of COPD subjects (post-bronchodilator $\mathrm{FEV}_{1} / \mathrm{FVC}<0.70$ ) than those without COPD smoked $>30$ packyears (66\% vs 39\%); similar results were found with the lower limit of normal definition. Analysis of exposure to biomass $>10$ y plus smoking $>20$ pack-years (reference was no exposure) found that tobacco smoking (crude odds ratio [OR] 4.50, 95\% CI 2.73-7.41; adjusted OR 3.30, 95\% CI 1.93-5.63) and biomass exposure (crude OR 3.66, 95\% CI 2.00-6.73; adjusted OR 2.28, 95\% CI 1.18-4.41) were risk factors for COPD, with smoking a possible confounder for the association between biomass and COPD (post-bronchodilator $\mathrm{FEV}_{\mathbf{1}} / \mathrm{FVC}<0.70$ ); similar results were found with the lower limit of normal definition. CONCLUSIONS: Subjects with COPD from primary care had a higher exposure to biomass and smoking compared with non-COPD subjects. Smoking and biomass are both risk factors for COPD, but they do not appear to have an additive effect. Key words: COPD; smoke; biomass exposure; primary care. [Respir Care 2017;62(8):1058-1066. (C) 2017 Daedalus Enterprises]
\end{abstract}

\section{Introduction}

COPD is a disease of high prevalence, morbidity, and mortality worldwide and is associated with exposure to toxic particles and smoke. ${ }^{1-9}$ Although smoking (tobacco

\footnotetext{
Drs Montes de Oca, Moreno, and Laucho-Contreras are affiliated with the Servicio de Neumonología, Hospital Universitario de Caracas, Facultad de Medicina, Universidad Central de Venezuela, Caracas, Venezuela. Dr Zabert is affiliated with the Facultad de Ciencias Médicas Universidad del Comahue, Rio Negro, Argentina. Dr Lopez Varela is affiliated with the Universidad de la República, Facultad de Medicina, Hospital Maciel, Montevideo, Uruguay. Dr Surmont is affiliated with Medical Affairs, AstraZeneca Latin America, Miami, FL, USA.
}

consumption) is widely recognized as the most important risk factor for COPD, it is now also recognized that a substantial proportion of COPD cases (one quarter to

\footnotetext{
This study was funded by AstraZeneca Latin America. Dr Surmont is an employee of AstraZeneca Latin America. The other authors have disclosed no conflicts of interest.

Correspondence: María Montes de Oca MD, Hospital Universitario de Caracas, Facultad de Medicina, Los Chaguaramos, 1030, Universidad Central de Venezuela, Caracas, Venezuela. E-mail: montesdeoca. maria@gmail.com.
}

DOI: $10.4187 /$ respcare. 05440 
one third of all cases) cannot be explained only by smoking, and the disease also occurs in non-smokers. A statement by the American Thoracic Society on novel risk factors and the global burden of COPD reported that the population-attributable fraction for smoking as a cause of COPD was $<80 \%$ of those involved in most clinical studies, indicating that other risk factors in addition to cigarette smoking are important in the development of the disease. ${ }^{10}$

The Latin American Project for the Investigation of Lung Disease (PLATINO) population-based study showed that among 5,315 subjects studied, 2,278 had never smoked, and 3,036 were current or ex-smokers. COPD was observed in $3.5 \%$ of those who had never smoked and in $7.5 \%$ of those who had smoked. ${ }^{11}$ The prevalence of COPD in those who have never smoked has also been reported in other population-based studies. ${ }^{12-15}$

The results of these population-based studies suggest that predictors of COPD in those who have never smoked include older age, female sex, a prior diagnosis of asthma or tuberculosis, lower education level, increased body mass index, exposure to environmental tobacco smoke or coal and/or biomass smoke, poor ventilation in the kitchen, a family history of respiratory disease, and childhood respiratory diseases. ${ }^{11-13}$ However, it has been suggested that some of these less traditional COPD risk factors, in particular biomass exposure, may interact with smoking to further increase the risk of COPD. Moreover, Lopez-Campos et al ${ }^{16}$ showed that subjects with COPD who were exposed to both tobacco and biomass smoke had increased oxygen usage and decreased quality of life.

There is a relative lack of information from the primary care setting regarding the history of smoking and biomass exposure in patients with and without COPD as well as on the possible additive effect among these exposures to increase the risk of COPD. Recently, the PUMA (Prevalence Study and Regular Practice, Diagnosis, and Treatment Among General Practitioners in Populations at Risk of COPD in Latin America) study, conducted in a primary care setting, evaluated the prevalence of air flow limitation in a population at risk for COPD. ${ }^{17,18}$ This study offered a good opportunity to assess different aspects of the disease in a large international primary care sample from Latin America. Therefore, the aims of the present study were to: (1) describe the history of smoking and biomass exposure in this primary care population; (2) analyze the exposure to biomass and smoking in COPD (using different spirometric definitions) and non-COPD subjects; and (3) measure the association between biomass exposure and tobacco smoking (pack-years) and COPD (using different spirometric definitions).

\section{QUICK LOOK}

\section{Current knowledge}

COPD is associated with exposure to toxic particles and smoke. Although smoking (tobacco consumption) is widely recognized as the most important risk factor for COPD, it is now also recognized that a substantial proportion of COPD cases cannot be explained only by smoking. It has been suggested that the interaction of some less traditional COPD risk factors, such biomass exposure, with smoking might further increase the risk of COPD.

\section{What this paper contributes to our knowledge}

In a primary care setting in 4 Latin American countries, approximately $40 \%$ of subjects with COPD reported exposure to biomass versus $30 \%$ of those without COPD. A higher proportion of subjects with COPD than those without COPD smoked $>30$ pack-years (66\% vs $39 \%)$. Biomass exposure $(>10 \mathrm{y})$ and tobacco smoking $(>20$ pack-years) (no exposure as reference) were risk factors for COPD, but they do not appear to have an additive effect.

\section{Methods}

The PUMA study was conducted in primary care settings in Argentina, Colombia, Venezuela, and Uruguay. The complete methodology has been published elsewhere. ${ }^{17-20}$ Briefly, this was a multi-center, multinational, cross-sectional, non-interventional study including primary care centers without direct connection with respiratory medicine specialists that were selected to reflect national primary care practice in terms of geographical distribution and health-care sector. Subjects were recruited during routine spontaneous or scheduled medical appointments unrelated to the study (with or without symptoms). The study was approved by the ethics committees for each site. All subjects provided written informed consent.

At-risk subjects were included if they were $\geq 40 \mathrm{y}$ of age, current or ex-smokers ( $\geq 10$ pack-years, $\geq 50$ pipes/y, or $\geq 50$ cigars/y), and/or exposed to biomass smoke (wood or coal for cooking or heating; exposure $\geq 100 \mathrm{~h} / \mathrm{y}$ ). Participants completed a modified version of the PLATINO study questionnaire ${ }^{1}$ for information on factors potentially associated with COPD; these included demographics, smoking habits, biomass exposure, education, employment, respiratory symptoms, use of respiratory medication, and prior spirometric testing. Data on prior medical diagnosis of tuberculosis, asthma, chronic bronchitis, emphysema, COPD, self-reported exacerbations, and hospitalizations 
were also obtained. Spirometry was performed using the portable, battery-operated ultrasound Easy One spirometer (ndd Medical Technologies, Zurich, Switzerland). Spirometry tests were performed at baseline and $15 \mathrm{~min}$ after the administration of $400 \mu \mathrm{g}$ of salbutamol, according to the American Thoracic Society criteria of acceptability and reproducibility.

The definition of COPD proposed by the Global Initiative for Chronic Obstructive Lung Disease was used: postbronchodilator $\mathrm{FEV}_{1} / \mathrm{FVC}<0.70 .{ }^{21}$ The post-bronchodilator lower limit of normal for $\mathrm{FEV}_{1} / \mathrm{FVC}$ criteria was also used. Smoking was defined by pack-years $(\leq 20,20-30$, or $>30$ ), and biomass exposure was defined as the history of exposure to coal or wood (for heating, cooking, or both) at for $\geq 10 \mathrm{y}$.

\section{Statistical Analysis}

We performed descriptive analysis using relative frequencies for the variables and comparison of the groups with and without COPD using a chi-square test for heterogeneity. Also, the mean duration of tobacco exposure (smoked pack-years) and of biomass exposure were obtained.

For the crude and adjusted models, we used a logistic regression analysis to determine odds ratios (ORs) and the respective 95\% CIs. For the adjusted model, we used as confounders the following variables: sex (male/female), age (complete years), skin color (white/non-white), schooling (complete years of formal education), body mass index $\left(\mathrm{kg} / \mathrm{m}^{2}\right)$, modified Medical Research Council scale, cough (yes/no), and phlegm (yes/no). For the analysis of a possible association of tobacco smoking plus biomass with COPD, these measures were mutually adjusted. All analyses were performed using Stata release 13 (StataCorp, College Station, Texas). $P$ values $<.05$ were considered statistically significant.

\section{Results}

Participation rates in the PUMA study have been published previously. ${ }^{17-20}$ Among the 1,743 subjects who completed interviews, 1,540 had acceptable spirometry. Based on post-bronchodilator $\mathrm{FEV}_{1} / \mathrm{FVC}<0.70$ criteria, $\mathrm{COPD}$ was present in 309 subjects and was present in 226 subjects using lower limit of normal criteria.

Baseline demographics and characteristics of subjects with or without COPD in the PUMA population, according to post-bronchodilator $\mathrm{FEV}_{1} / \mathrm{FVC}<0.70$ and lower limit of normal criteria, are shown in Table 1. As expected, subjects with COPD (defined using either criteria) were older, predominantly male, had a lower body mass index $\left(<25 \mathrm{~kg} / \mathrm{m}^{2}\right)$, reported more respiratory symptoms (dyspnea, cough, and phlegm), had more self-reported asthma, and had a modified Medical Research Council score of $\geq 2$ compared with those without COPD.

Exposure to biomass for $>10 \mathrm{y}$ and to tobacco smoke for $\geq 10$ pack-years in subjects with COPD according to post-bronchodilator $\mathrm{FEV}_{1} / \mathrm{FVC}<0.70$ criteria and lower limit of normal criteria are shown in Figures 1 and 2, respectively. Irrespective of the COPD definition used, a greater proportion of subjects with COPD (approximately 40\%) reported exposure to biomass in comparison with subjects without COPD (approximately 30\%) (Fig. 1). A greater proportion of subjects with COPD, defined by postbronchodilator $\mathrm{FEV}_{1} / \mathrm{FVC}<0.70$, compared with subjects without COPD, smoked $>30$ pack-years (66\% vs $39 \%$ ); similar results were found for COPD according to the lower limit of normal criteria (Fig. 2).

The mean number of pack-years smoked and the mean years of biomass exposure in subjects with COPD, using either definition of COPD, were higher than in those with COPD than in those without the disease (Fig. 3). Subjects with COPD, for both definitions, had an average of 44 pack-years of tobacco smoking and $12 \mathrm{y}$ of biomass exposure (Fig. 3).

The association between biomass exposure and tobacco smoking (pack-years smoked) with COPD is shown in Table 2. Biomass exposure ( $>10 \mathrm{y}$ ) was found to be a risk factor for COPD (defined using both criteria) in the crude analysis, with the risk of COPD increasing with increased exposure (Table 2); however, this did not reach statistical significance in the adjusted analysis (subjects who were exposed to biomass could be also smokers; therefore, they could be exposed to both biomass and smoke). The lack of statistical significance in the adjusted analysis could be due to the concomitant presence of smoking. Smoking $>20$ pack-years was found to be a risk factor for COPD (defined using both criteria) in both the crude and adjusted analysis, with increased smoking further increasing the risk of COPD (Table 2). In the analysis of exposure to biomass and/or smoking, it would appear that whereas both tobacco smoking and biomass exposure are risk factors for COPD (the unique effects of those only exposed to biomass or to smoking are significant), the adjusted OR might suggest that smoking is a possible confounding factor for the association between biomass and COPD (Table 2).

\section{Discussion}

The main findings of this study on tobacco smoke, biomass exposure, and COPD risk in a primary care setting were as follows. First, a higher proportion of subjects with COPD reported exposure to biomass and tobacco smoke compared with those without COPD, and the most frequent source of biomass exposure was cooking. Second, increased tobacco smoking and biomass exposure further 
Table 1. Baseline Demographics and Characteristics of Subjects With and Without COPD, According to Post-Bronchodilator FEV $/ \mathrm{FVC}<0.70$ and Lower Limit of Normal Criteria

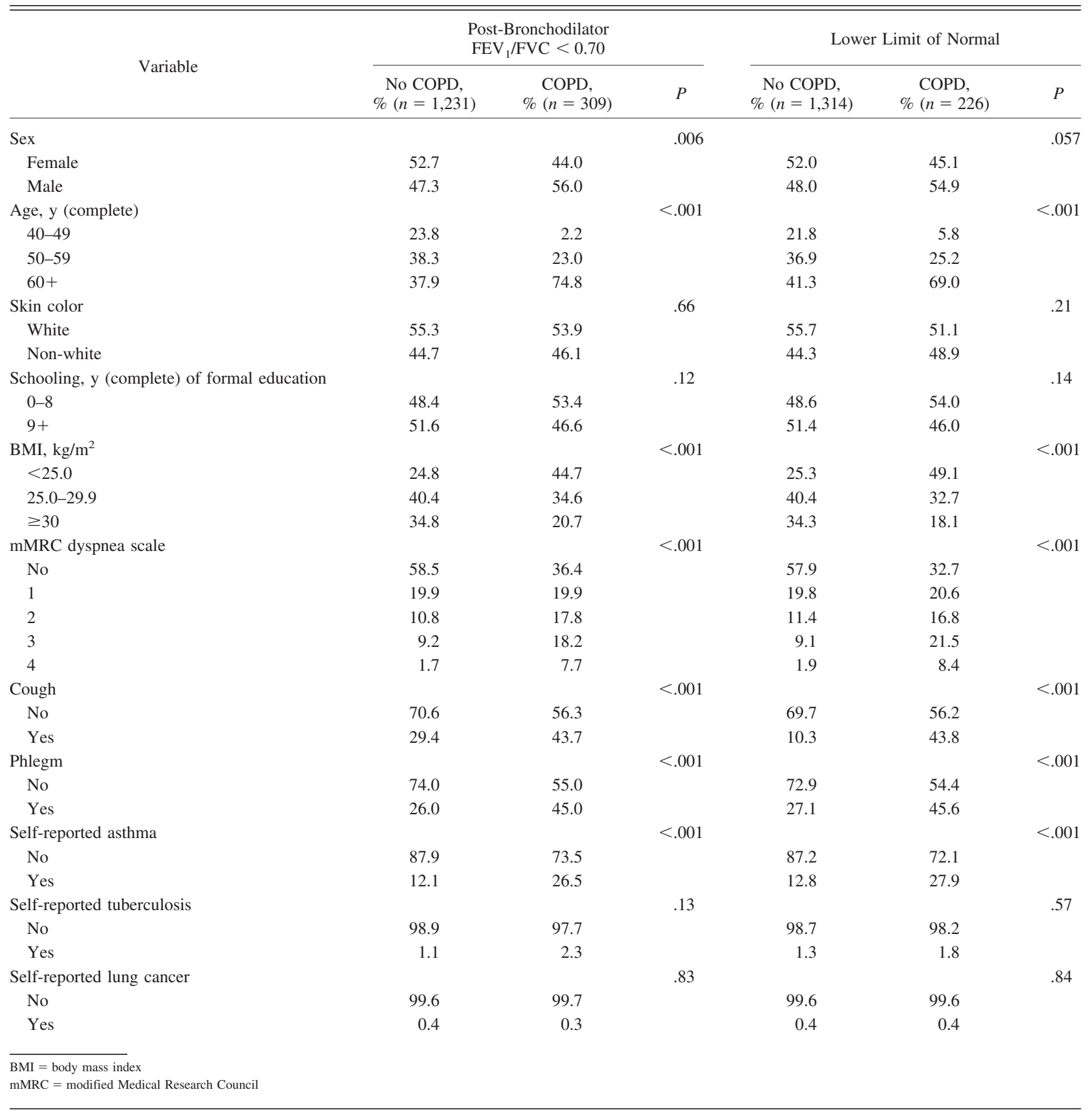

increased the risk of COPD, but smoking appeared to be a confounding factor for the association of biomass and COPD.

The major effects of smoking in COPD have been extensively documented for many years. Several populationbased studies in primary care settings have reported the smoking pattern in subjects with and without COPD. ${ }^{22-24}$ In the PLATINO study, tobacco smoking was higher in subjects with COPD compared with those without COPD (19.4 vs 9.1 pack-years). The proportions of current smokers and ex-smokers were also higher in those with COPD than in those without the disease (current smokers: $36.0 \%$ vs $28.8 \%$; ex-smokers: $32.5 \%$ vs $26.8 \%$ ). ${ }^{22}$ In addition, both females and males with COPD reported higher tobacco smoking compared with persons without COPD (females: 11.6 pack-years vs 6.0 pack-years; males: 26.5 pack- 


\section{Smoke, Biomass Exposure, AND COPD Risk}

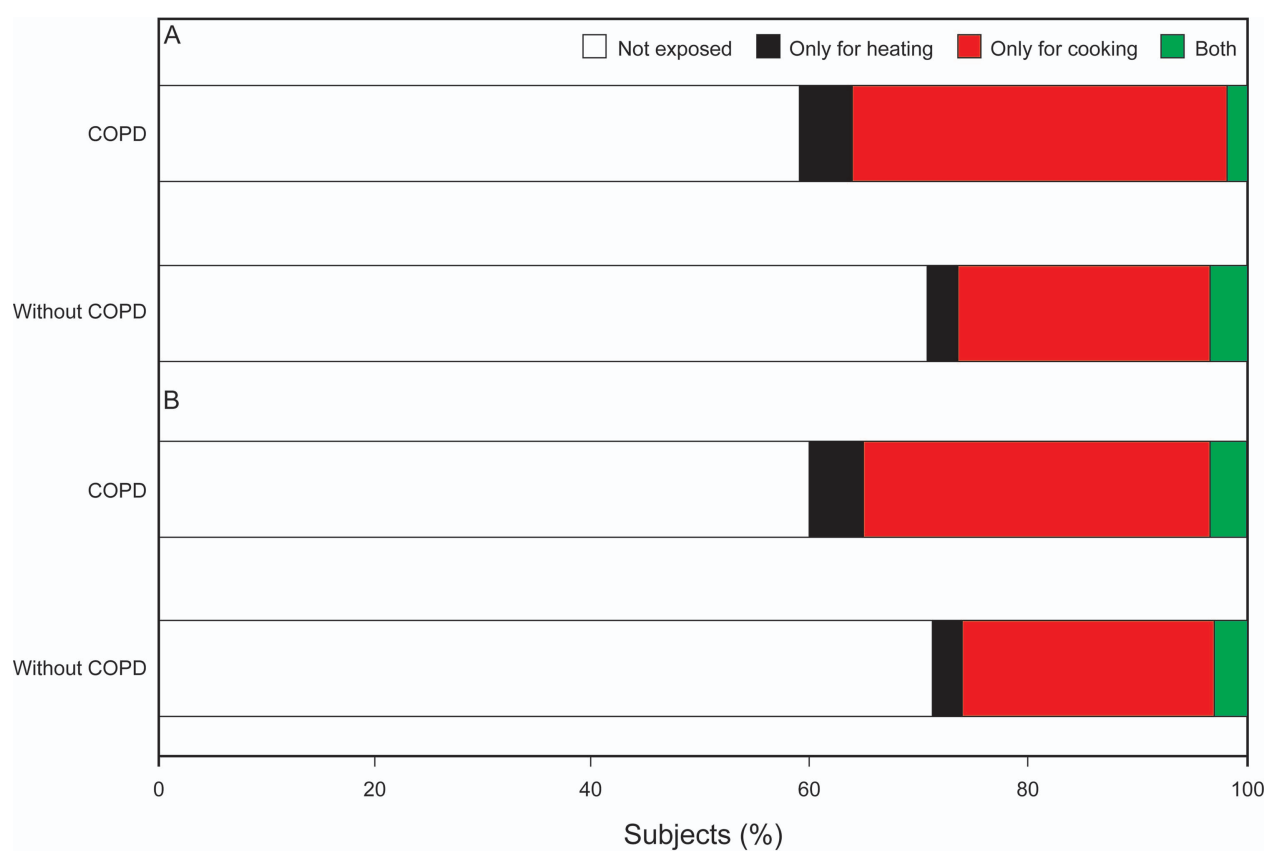

Fig. 1. Exposure to biomass (defined using lower limit of normal criteria $[\mathrm{A}]$ and post-bronchodilator $F E V_{1} / F V C<0.70[B]$ ) in subjects with and without COPD.

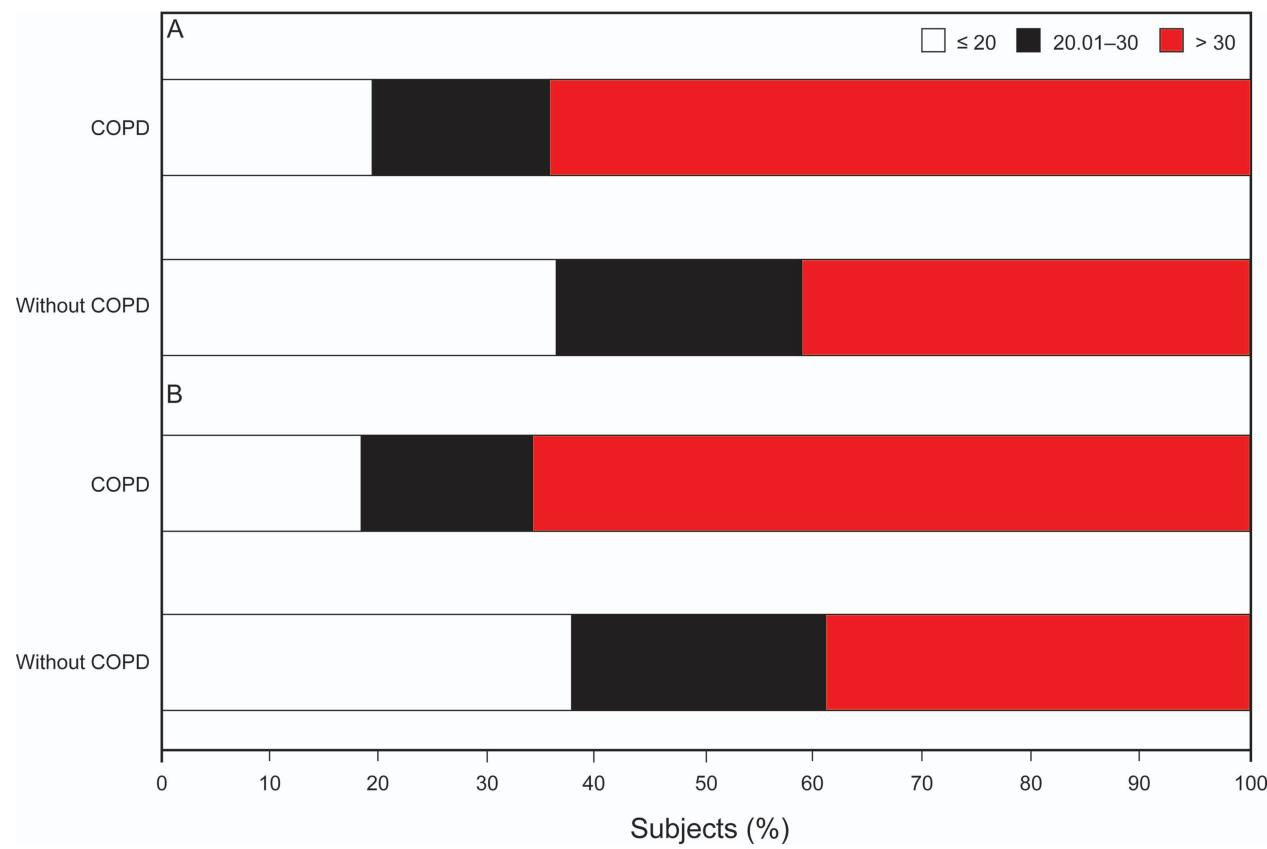

Fig. 2. Exposure to pack-years smoked (defined using lower limit of normal criteria $[A]$ and post-bronchodilator $F E V_{1} / F V C<0.70[B]$ ) in subjects with and without COPD.

years vs 14.1 pack-years). ${ }^{23}$ Data from a primary care study of subjects at least $45 \mathrm{y}$ of age and with a history of smoking showed that subjects with COPD have a higher smoking index than those without COPD (52.6 pack-years vs 32.1 pack-years). ${ }^{24}$ The results of the present analysis indicate that a larger proportion of subjects with COPD than those without COPD smoked $>30$ pack-years $(66 \%$ vs $39 \%$ ). The proportion of subjects who smoked $\leq 20$ pack-years was only $18 \%$ in the group with COPD (defined as post-bronchodilator $\mathrm{FEV}_{1} / \mathrm{FVC}<0.70$ ) and $37.5 \%$ in those without the disease. Our results, therefore, are consistent with previous reports and argue in favor of smok- 

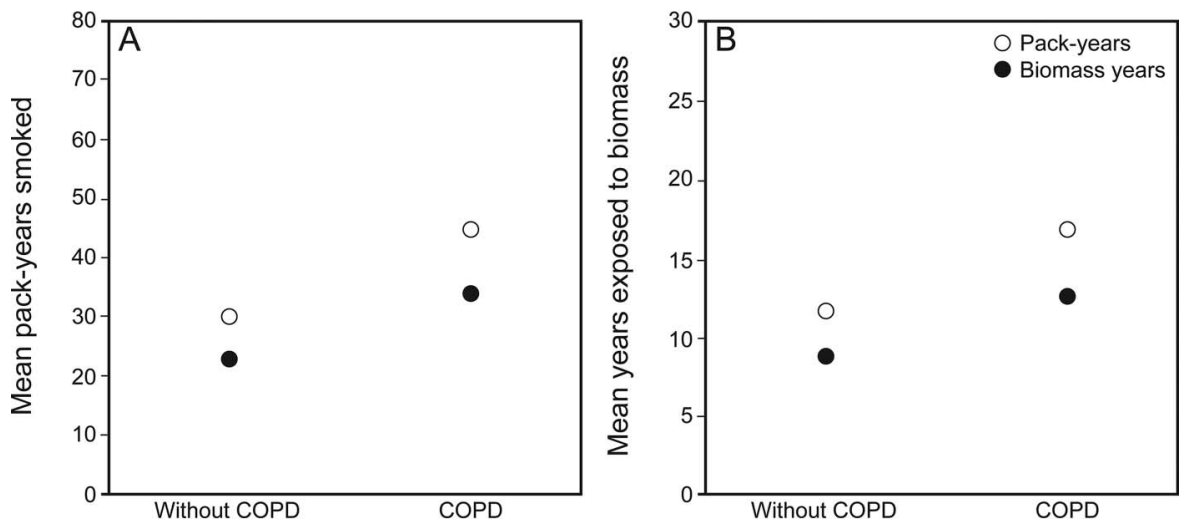

Fig. 3. Exposure to biomass (mean years) and pack-years smoked (defined using post-bronchodilator FEV $_{1} / \mathrm{FVC}<0.70[\mathrm{~A}]$ and lower limit of normal criteria $[\mathrm{B}]$ ) in subjects with and without COPD.

Table 2. Association of Biomass Exposure and Tobacco Smoking With COPD

\begin{tabular}{|c|c|c|c|c|c|c|c|c|}
\hline \multirow[b]{2}{*}{ Variable } & \multicolumn{4}{|c|}{ Post-Bronchodilator $\mathrm{FEV}_{1} / \mathrm{FVC}<0.70$} & \multicolumn{4}{|c|}{ Lower Limit of Normal } \\
\hline & $\begin{array}{c}\text { Crude } \\
\text { OR }(95 \% \mathrm{CI})\end{array}$ & $P$ & $\begin{array}{c}\text { Adjusted } \\
\text { OR }(95 \% \mathrm{CI})\end{array}$ & $P$ & $\begin{array}{c}\text { Crude } \\
\text { OR }(95 \% \text { CI })\end{array}$ & $P$ & $\begin{array}{c}\text { Adjusted } \\
\text { OR }(95 \% \text { CI })\end{array}$ & $P$ \\
\hline Biomass, y exposed & & $<.001$ & & .26 & & .003 & & .62 \\
\hline 0 & 1.00 & & 1.00 & & 1.00 & & 1.00 & \\
\hline$>0-10$ & $1.57(1.10-2.24)$ & & $1.27(0.84-1.93)$ & & $1.18(0.78-1.77)$ & & $0.90(0.56-1.44)$ & \\
\hline$>10$ & $2.02(1.50-2.73)$ & & $1.34(0.92-1.96)$ & & $1.75(1.26-2.44)$ & & $1.15(0.76-1.74)$ & \\
\hline Biomass, y exposed & & $<.001$ & & .25 & & .001 & & .57 \\
\hline $0-10$ & 1.00 & & 1.00 & & 1.00 & & 1.00 & \\
\hline$>10$ & $1.75(1.33-2.30)$ & & $1.23(0.87-1.74)$ & & $1.67(1.23-2.26)$ & & $1.19(0.81-1.75)$ & \\
\hline Pack-years smoked & & $<.001$ & & $<.001$ & & $<.001$ & & $<.001$ \\
\hline$\leq 20$ & 1.00 & & 1.00 & & 1.00 & & 1.00 & \\
\hline$>20-30$ & $1.44(0.94-2.23)$ & & $1.41(0.87-2.29)$ & & $1.33(0.82-2.16)$ & & $1.27(0.75-2.17)$ & \\
\hline$>30$ & $3.67(2.62-5.19)$ & & $2.63(1.80-3.84)$ & & $3.13(2.15-4.56)$ & & $2.25(1.48-3.40)$ & \\
\hline Pack-years smoked & & $<.001$ & & $<.001$ & & $<.001$ & & .001 \\
\hline$\leq 20$ & 1.00 & & 1.00 & & 1.00 & & 1.00 & \\
\hline$>20$ & $2.84(2.04-3.95)$ & & $2.21(1.54-3.18)$ & & $2.48(1.72-3.57)$ & & $1.91(1.28-2.85)$ & \\
\hline $\begin{array}{c}\text { Biomass }(>10 \text { y) and/or } \\
\text { pack-years }(>20)\end{array}$ & & $<.001$ & & $<.001$ & & $<.001$ & & .006 \\
\hline No exposure & 1.00 & & 1.00 & & 1.00 & & 1.00 & \\
\hline Only biomass & $3.66(2.00-6.73)$ & & $2.28(1.18-4.41)$ & & $3.23(1.66-6.27)$ & & $2.14(1.05-4.36)$ & \\
\hline Only pack-years & $4.50(2.73-7.41)$ & & $3.30(1.93-5.63)$ & & $3.73(2.16-6.43)$ & & $2.80(1.56-5.03)$ & \\
\hline Both & $6.94(4.08-11.80)$ & & $3.43(1.87-6.29)$ & & $5.50(3.08-9.79)$ & & $2.77(1.42-5.39)$ & \\
\hline
\end{tabular}

Adjusted analyses were made using sex, age, skin color, schooling, body mass index, self-reported asthma diagnosis, Modified Medical Research Council scale for dyspnea, cough, and phlegm as confounding variables. All analyses were mutually adjusted for smoking and biomass.

$\mathrm{OR}=$ odds ratio

ing as a strong risk factor for COPD, with higher COPD risk with increased smoking, although this population already has a moderate-to-high tobacco use.

Although cross-sectional and cohort studies have consistently shown that smoking is one of the most important risk factors for COPD, a wide variation in the populationattributable fraction for smoking as a cause of COPD has been reported (ranging from 9.7 to $97.9 \%$ ). ${ }^{10}$ The evidence indicates that a substantial proportion of COPD cases can- not be attributed to smoking and that other risk factors are important in the development of COPD. ${ }^{11-13,25,26}$ In the PLATINO study, age, current smoking status, indoor exposure to coal, and exposure to dust in the workplace were the risk factors presenting the highest etiological fractions for COPD. ${ }^{1}$ Attributable risk for COPD was $52 \%$ for being $\geq 60 \mathrm{y}$ of age, and for modifiable risk factors, the risk was $27 \%$ for being a current smoker, $11 \%$ for exposure to coal for $\geq 10 \mathrm{y}$, and $9 \%$ for exposure to dust in the workplace 
for $\geq 10 \mathrm{y}$. Other factors, including male sex, poor education, exposure to biomass, history of tuberculosis, low body mass index, and childhood admission due to respiratory problems, presented an attributable risk $<10 \%{ }^{1}$

A sub-analysis of the BOLD program assessed the risk factors for COPD, and it found significant associations between COPD and smoking, environmental tobacco exposure, age, education, tuberculosis, hospitalization for respiratory illness before the age of $10 \mathrm{y}$, a family history of COPD, and working in dusty jobs. ${ }^{26}$ Additional evidence for the contribution of other risk factors besides smoking results from the occurrence of COPD in those who have never smoked, with a prevalence ranging from 3 to $15 \%$ in different populations. ${ }^{12,13,25,27}$ The PLATINO study reported a COPD prevalence of 3.5 and $7.5 \%$ in those who had never smoked and current/ex-smokers, respectively. ${ }^{11}$ Terzikhan et $\mathrm{al}^{25}$ found that COPD prevalence was $17.8 \%$ in smokers and $6.4 \%$ in non-smokers. The overall prevalence of COPD among non-smokers was $5.2 \%$ in a large Chinese population-based study ${ }^{12}$ and $6.4 \%$ in a Canadian study (representing 27\% of all COPD subjects). ${ }^{27}$ Using Global Initiative for Chronic Obstructive Lung Disease criteria to define COPD, the BOLD study reported an overall prevalence of 5.2\% in those who had never smoked, which represented $27.7 \%$ (523 of 1,889) of all COPD cases. ${ }^{13}$ They identified that female sex, increased age, prior diagnosis of asthma, childhood infections, organic dust, and lower education levels were all associated with increased risk for COPD among those who had never smoked. ${ }^{13}$

The relationship between exposure to indoor biomass smoke and the development of COPD continues to be an area of controversy. The results of a meta-analysis showed that persons exposed to biomass smoke have an OR of 2.44 (95\% CI 1.90-3.33) for the development of COPD compared with those unexposed..$^{28}$ The study also reported that exposure to tobacco smoke was a risk factor for the development of COPD in both sexes, although whether an interaction exists between these risk factors remains unclear. ${ }^{28}$ Another meta-analysis established that biomass exposure is associated with risk of COPD, but smoking status was not taken into account. ${ }^{29}$ In the BOLD study, biomass exposure was not different between those with or without COPD; however, when subjects with COPD were grouped by air-flow limitation severity, those with moderate to severe COPD reported more frequently a history of biomass exposure than control subjects. ${ }^{13}$ Zhong et al ${ }^{30}$ showed that biomass exposure was associated with an increased risk of developing COPD among a Chinese population, and the CanCOLD study showed that the relationship between biomass exposure and COPD remained when the analysis was adjusted for sex..$^{27}$

Our findings are consistent with most of the previous studies in that biomass exposure is a risk factor for devel- oping COPD. Moreover, a higher proportion of our COPD subjects reported exposure to biomass than those without COPD. A possible explanation for the discrepancies with other studies (BOLD or CanCOLD) could be the result of differences in the population studied (primary care setting vs population-based) and the source of biomass exposure (heating vs indoor cooking).

It has been postulated that some of the less traditional risk factors may interact with smoking to further increase the risk of COPD. However, few studies have compared the 2 smoke-related risk factors in the same population, and even fewer studies have tried to assess the interaction between these 2 factors for developing COPD. There are some important limitations when exploring this relationship, which include the different patterns of smoke exposure and measurement of the magnitude of each exposure. Most exposure estimations cannot predict the dose of contaminant and generally only estimate exposure time..$^{31,32}$ The main exception is tobacco smoking, because packyears has been validated for cumulative smoking exposure as a risk factor for many diseases. This level of validation, without air quality measurement (particle pollution) or exposure biomarkers (eg, $\mathrm{CO}$ in exhaled air), is still in development or is lacking for exposure to other types of smoke (eg, biomass or other smoking, such as water-pipe or marijuana). Despite this limitation, some reports have explored these relationships.

Sood et $\mathrm{a}^{33}$ determined whether wood smoke exposure was a risk factor for COPD in a current smoker population and whether aberrant gene promoter methylation in sputum modified this association. Their findings indicate that wood smoke exposure was independently associated with a lower $\mathrm{FEV}_{1}$ and a higher prevalence of air-flow obstruction and chronic bronchitis, and these associations were stronger among current tobacco smokers. In addition, smokers who expressed aberrant promoter methylation of the p16 and GATA4 genes in sputum demonstrated stronger associations of wood smoke exposure and lower lung function than those without these epigenetic changes. ${ }^{33}$ Another relevant finding in the study was that New Mexican non-Hispanic white persons were at greater risk for wood smoke-associated COPD than Hispanic persons in general. The authors concluded that exposure to wood smoke and gene promoter methylation synergistically increased the risk of reduced lung function in cigarette smokers, which supports an additive effect between current cigarette smoking and wood smoke exposure on some COPD phenotypes. ${ }^{33}$ Other authors also reported a significant negative correlation between biomass exposure and lung function, as well as a significant synergistic effect between smoking history and biomass exposure in terms of loss of lung function in a population $\geq 18$ y of age. ${ }^{34}$

In contrast, a case-control Chinese study showed an increased risk of developing COPD associated with to- 


\section{Smoke, Biomass Exposure, AND COPD Risk}

bacco smoking but not with biomass exposure nor with both risk factors. ${ }^{35}$ However, a major limitation was that the authors did not explain the biomass exposure time estimation or the tobacco index.

Although our findings showed that tobacco smoking and biomass exposure are risk factors for COPD, they also indicate that smoking seemed to be a confounding factor for biomass. Therefore, they do not allow us to support a possible synergistic or additive effect between these risk factors that further increases the risk of COPD. One possible explanation for this is that the PUMA study evaluated an older population located in major cities in Latin America, whereas, for example, da Silva et al ${ }^{34}$ studied a younger, rural population, whereas Sood et $\mathrm{al}^{33}$ evaluated a New Mexican population. Overall, the lack of similar information from other multinational studies in a primary care setting from our region makes it difficult to compare results with the PUMA study.

This study has some limitations that should be highlighted. We acknowledge that the findings from this study cannot be extrapolated to all Latin American countries, because the study was only performed in 4 countries; this was the result of limited resources within the countries and the availability of centers to participate. Nevertheless, the study procedure used was the most sensible, given the operational possibilities in each country. Another limitation is that this was a transversal study and so was only designed to evaluate the characteristics of the subjects, and there was no follow-up; we did not assess any pathophysiological link for risk factors and COPD that could help to explain the findings. The difficulties in measuring exposure to biomass (self-reported history) could be another limitation when measuring the impact of this risk factor in the development of COPD. The associations between exposure to biomass and COPD tend to nullity due to the way biomass was measured. Unfortunately, more detailed information on biomass exposure was not collected, and further studies need to address this important issue for a better understanding of the real effect of biomass on COPD. Finally, due to the design of the PUMA study, there were no subjects without exposure to risk factors in the study population.

\section{Conclusions}

The results of the present study indicate that subjects with COPD from primary care in Latin America had a higher exposure to biomass and tobacco smoke compared with those without the disease. Smoking and biomass exposure are both risk factors for COPD, but they do not seem to have an additive effect on the risk of COPD.

\section{ACKNOWLEDGMENTS}

Editorial support was provided by Ian Wright of Wright Medical Communications Ltd.

\section{REFERENCES}

1. Menezes AMB, Perez-Padilla R, Jardim JRB, Muiño A, Lopez MV Valdivia $\mathrm{G}$, et al. Chronic obstructive pulmonary disease in five Latin American cities (the PLATINO study): a prevalence study. Lancet 2005;366(9500):1875-1881.

2. Mannino DM, Buist AS. Global burden of COPD: risk factors, prevalence, and future trends. Lancet 2007;370(9589):765-773.

3. Buist AS, McBurnie MA, Vollmer WM, Gillespie S, Burney P, Mannino DM, et al. International variation in the prevalence of COPD (the BOLD Study): a population-based prevalence study. Lancet 2007;370(9589):741-750. Erratum in: Lancet 2012;380(9844):806.

4. López-Campos JL, Ruiz-Ramos M, Soriano JB. Mortality trends in chronic obstructive pulmonary disease in Europe, 1994-2010: a joinpoint regression analysis. Lancet Respir Med 2014;2(1):54-62.

5. Rycroft CE, Heyes A, Lanza L, Becker K. Epidemiology of chronic obstructive pulmonary disease: a literature review. Int J Chron Obstruct Pulmon Dis 2012;7:457-494.

6. Menezes AM, Pérez-Padilla R, Wehrmeister FC, Lopez-Varela MV, Muiño A, Valdivia G, et al. $\mathrm{FEV}_{1}$ is a better predictor of mortality than FVC: the PLATINO cohort study. PLoS One 2014;9(10): e109732.

7. To T, Stanojevic S, Moores G, Gershon AS, Bateman ED, Cruz AA, Boulet LP. Global asthma prevalence in adults: findings from the cross-sectional world health survey. BMC Public Health 2012;12: 204.

8. GBD 2013 Mortality and Causes of Death Collaborators. Global, regional, and national age-sex specific all-cause and cause-specific mortality for 240 causes of death, 1990-2013: a systematic analysis for the Global Burden of Disease Study 2013. Lancet 2015;385(9963): 117-171.

9. Burney P, Jarvis D, Perez-Padilla R. The global burden of chronic respiratory disease in adults. Int J Tuberc Lung Dis 2015;19(1):1020.

10. Eisner MD, Anthonisen N, Coultas D, Kuenzli N, Perez-Padilla R, Postma D, et al. An official American Thoracic Society public policy statement: novel risk factors and the global burden of chronic obstructive pulmonary disease. Am J Respir Crit Care Med 2010;182(5): 693-718.

11. Perez-Padilla R, Fernandez R, Lopez Varela MV, Montes de Oca M, Muiño A, Tálamo C, et al. Airflow obstruction in never smokers in five Latin American cities: the PLATINO study. Arch Med Res 2012;43(2):159-165.

12. Zhou Y, Wang C, Yao W, Chen P, Kang J, Huang S, et al. COPD in Chinese nonsmokers. Eur Respir J 2009;33(3):509-518.

13. Lamprecht B, McBurnie MA, Vollmer WM, Gudmundsson G, Welte T, Nizankowska-Mogilnicka E, et al. COPD in never smokers: results from the population-based burden of obstructive lung disease study. Chest 2011;139(4):752-763.

14. Kim DS, Kim YS, Jung KS, Chang JH, Lim CM, Lee JH, et al. Prevalence of chronic obstructive pulmonary disease in Korea: a population based spirometry survey. Am J Respir Crit Care Med 2005;172(7):842-847.

15. Celli BR, Halbert RJ, Isonaka S, Schau B. Population impact of different definitions of airway obstruction. Eur Respir J 2003;22(2): 268-273.

16. López-Campos JL, Fernández-Villar A, Calero-Acuña C, RepresasRepresas C, López-Ramírez C, Fernández VL, et al. Occupational and biomass exposure in chronic obstructive pulmonary disease: 


\section{SMOKe, Biomass Exposure, AND COPD Risk}

results of a cross-sectional analysis of the On-Sint study. Arch Bronconeumol 2017;53(1):7-12.

17. López Varela MV, Montes de Oca M, Rey A, Casas A, Stirbulov R, Di Boscio V. Opportunistic COPD case-finding in primary care of four Latin America countries. Developing a simple screening tool: the PUMA study. Respirology 2016;21(7):1227-1234.

18. Casas Herrera A, Montes de Oca M, López Varela MV, Aguirre C, Schiavi E, Jardim JR. COPD underdiagnosis and misdiagnosis in a high-risk primary care population in four Latin American countries: a key to enhance disease diagnosis: the PUMA study. PLoS One 2016;11(4):e0152266.

19. Schiavi E, Stirbulov R, Hernández Vecino R, Mercurio S, Di Boscio V. COPD screening in primary care in four Latin American countries: methodology of the PUMA study. Arch Bronconeumol 2014; 50(11):469-474

20. Montes de Oca M, Lopez Varela MV, Jardim J, Stirvulov R, Surmont $\mathrm{F}$. Bronchodilator treatment for COPD in primary care of four Latin America countries: the multinational, cross-sectional, non-interventional PUMA study. Pulm Pharmacol Ther 2016;38:10-16.

21. Vestbo J, Hurd SS, Agustí AG, Jones PW, Vogelmeier C, Anzueto A, et al. Global strategy for the diagnosis, management, and prevention of chronic obstructive pulmonary disease: GOLD executive summary. Am J Respir Crit Care Med 2013;187(4):347-365.

22. López Varela MV, Montes de Oca M, Halbert R, Muiño A, Tálamo C, Pérez-Padilla R, et al. Comorbidities and health status in individuals with and without COPD in five Latin American cities: the PLATINO study. Arch Bronconeumol 2013;49(11):468-474.

23. Lopez Varela MV, Montes de Oca M, Halbert RJ, Muiño A, PerezPadilla R, Tálamo C, et al. Gender related difference in COPD in five Latin American cities: The PLATINO study. Eur Respir J 2010; 36(5):1034-1041.

24. Llordés M, Jaén A, Almagro P, Heredia JL, Morera J, Soriano JB, Miravitlles M. Prevalence, risk factors and diagnostic accuracy of COPD among smokers in primary care. COPD 2015;12(4):404-412.

25. Terzikhan N, Verhamme KM, Hofman A, Stricker BH, Brusselle GG, Lahousse L. Prevalence and incidence of COPD in smokers and nonsmokers: the Rotterdam Study. Eur J Epidemiol 2016;31(8):785-792.
26. Hooper R, Burney P, Vollmer WM, McBurnie MA, Gislason T, Tan WC, et al. Risk factors for COPD spirometrically defined from the lower limit of normal in the BOLD project. Eur Respir J 2012;39(6): 1343-1353.

27. Tan WC, Sin DD, Bourbeau J, Hernandez P, Chapman KR, Cowie $\mathrm{R}$, et al. Characteristics of COPD in never-smokers and ever-smokers in the general population: results from the CanCOLD study. Thorax 2015;70(9):822-829.

28. Hu G, Zhou Y, Tian J, Yao W, Li J, Li B, Ran P. Risk of COPD from exposure to biomass smoke: a meta-analysis. Chest 2010;138(1):2031.

29. Kurmi OP, Semple S, Simkhada P, Smith WC, Ayres JG. COPD and chronic bronchitis risk of indoor air pollution from solid fuel: a systematic review and meta-analysis. Thorax 2010;65(3):221-228.

30. Zhong N, Wang C, Yao W, Chen P, Kang J, Huang S, et al. Prevalence of chronic obstructive pulmonary disease in China: a large, population-based survey. Am J Respir Crit Care Med 2007;176(8): 753-760.

31. Bruce N, Neufeld L, Boy E, West C. Indoor biofuel air pollution and respiratory health: the role of confounding factors among women in highland Guatemala. Int J Epidemiol 1998;27(3):454-458.

32. Jerrett M, Arain A, Kanaroglou P, Beckerman B, Potoglou D, Sahsuvaroglu $\mathrm{T}$, et al. A review and evaluation of intraurban air pollution exposure models. J Expo Anal Environ Epidemiol 2005;15(2): 185-204.

33. Sood A, Petersen H, Blanchette CM, Meek P, Picchi MA, Belinsky SA, Tesfaigzi Y. Wood smoke exposure and gene promoter methylation are associated with increased risk for COPD in smokers. Am J Respir Crit Care Med 2010;182(9):1098-1104.

34. da Silva LF, Saldiva SR, Saldiva PH, Dolhnikoff M. Impaired lung function in individuals chronically exposed to biomass combustion. Environ Res 2012;112:111-117.

35. Xu F, Yin X, Shen H, Xu Y, Ware RS, Owen N. Better understanding the influence of cigarette smoking and indoor air pollution on chronic obstructive pulmonary disease: a case-control study in Mainland China. Respirology 2007;12(6):891-897. 